\title{
Pyrethroid Based Mosquito Repellent Inhalation Induced Changes In Physical Activity In Albino Rats After Chronic Exposure
}

\author{
Saim Hasan*, Maheshwari T $\mathbf{P}^{* *}$ \\ *Assistant professor, Department of Anatomy, SHKM GMC, Nalhar, Mewat, Haryana. \\ *** Senior resident, Department of Anatomy, SHKM GMC, Nalhar, Mewat, Haryana.
}

\begin{abstract}
Introduction: The liquid vaporizers are very commonly used as residential insecticides in developing countries. Neurotoxic effects of pyrethroids have been reported earlier but study regarding its direct effect on physical activity of albino rats are scanty. So the present study was planned to assess and compare the effects of long term prallethrin (a Pyrethroid) exposure on albino rats.
\end{abstract}

Method: Twenty albino rats were divided into two groups of control and experimental. Rats in experimental group were exposed to $3.2 \% \mathrm{w} / \mathrm{v}$ prallethrin vapours 12 hours daily for 180 days. Control animals were kept under identical conditions without exposure to said repellent.

The albino rats in experimental group were subjected to Spontaneous Motor Activity, Forced Locomotor Activity and Swimming endurance test to record their physical activity.

Result: Significant changes in Spontaneous Motor Activity, Forced Locomotor Activity and Swimming Endurance Test were not recorded in prallethrin exposed rats as compared to control ones throughout the study.

Conclusion: Lack of changes in the behavioural parameters as seen in our study may be due to difference in the route adopted and perhaps due to limited duration of exposure and high degree of adaptability of the animal to adverse insults.

Index Terms- pyrethroids, liquid vaporizers, albino rats, physical activity, adaptability

\section{INTRODUCTION}

$\mathrm{T}$ The major types of residential insecticidal products include aerosols, mosquito coils and vaporizing mats among which the liquid vaporizers have outnumbered others in popularity. ${ }^{1}$ Their toxic effects have been observed in non target organs causing muscle pain, joint pain, ataxia, chronic fatigue, headache and difficulty in concentration.

Pyrethroid induced neurotoxicity and other toxic symptoms, and their deleterious effects in humans and experimental animals caused a concern on their chronic use. These compounds are being extensively used and the product information leaflet enclosed by the manufacturers are too ambiguous to ensure the safety profiles on prolonged usage to all groups including pregnant women. Most of the previous reports are based on studies on immature mammals who received drug through different routes except respiratory. The latter being conventional route through which millions of people are exposed for several decades. Hence the present study is aimed at investigating and evaluating the changes in various physical activity and psychomotor parameters in albino rats after inhalation of pyrethroid based mosquito repellent.

\section{MATERIAL AND MethoD}

The present study was carried out on adult Charles foster rats weighing between $100-150 \mathrm{gms}$. The animals were provided with standard pellet laboratory diet (Lipton India Limited) and water ad-libitum. They were housed under identical diurnal conditions and temperature. The animals were weighed, marked and divided into two groups:

Group 1-Experimental

Group 2-Control

The experimental animals were kept in unit plastic cages $(36 \mathrm{~cm} \times 22 \mathrm{~cm} \times 14 \mathrm{~cm})$ with many holes. They were exposed to liquid mosquito repellent inside a closed room $(180 \mathrm{~cm} \times 240 \mathrm{~cm})$ according to the method of Sinha. ${ }^{2}$ The animals were exposed to $3.2 \% \mathrm{w} / \mathrm{v}$ prallethrin vapours for $12 \mathrm{hrs}$ daily for a period of 180 days. The control animals were kept under identical conditions without exposure to $3.2 \% \mathrm{w} / \mathrm{v}$ prallethrin vapours. The permission to perform experiments on rats was taken from Institutional animal ethics committee.

The body weight was measured weekly and the water consumption was assessed daily.

On day zero that is before exposure, the weight and physical activities of both control and experimental rats were noted down.

The experiments performed to assess physical activity were,

1. Spontaneous Motor Activity

2. Forced Locomotor Activity

3. Swimming endurance test

Thereafter all these parameters were assessed at days 1,7 , $14,21,28,35,42,49,56,63,70,77,84,91,98,105,112,119$, $126,133,140,147,154,161,168,175$ and 180.

\section{Spontaneous Motor Activity}

Motor activity was recorded on "Digital Actophotometer" which has a chamber made up of perspex sheet for the animal. A variable shock of strength $100 \mathrm{~V}, 50 \mathrm{~Hz}, 0.2 \mathrm{~mA}$ is provided which 
is inbuilt in the instrument. Also a four digit counter is provided which counts the movement of animal inside the perspex chamber. Each animal was observed over a period of 5 minutes and values expressed as counts per 5 minutes. $^{3}$

\section{Forced Locomotor Activity (Rota Rod test)}

This test was performed according to the method of Kihara. ${ }^{4}$ Albino rats weighing 100-150 g were taken. The animals were placed individually on a scraped rod of $7 \mathrm{~cm}$ in diameter and rotating at a rate of 5 revolutions per minute. Animals were tested in two trials per day. The maximum trial duration was 180 seconds and the inter trial interval was about 30 minutes. The time that each animal remained on the rod at the rotation speed was recorded.

\section{Swimming Endurance Test}

This was done according to the method of Trudeau And Murphy. ${ }^{5}$ A group of seven rats were tested for swimming endurance. The rats were made to swim till exhaustion in a swimming pool. The apparatus measuring $90 \times 45 \times 70 \mathrm{~cm}$ in size was fitted with a thermostat. It was filled with water at a temperature of $37^{\circ} \mathrm{C}$ and the temperature was maintained throughout the experiment. The time taken to swim to exhaustion was calculated for each group by taking mean of individual time. The criterion for exhaustion was the animals inability to surface for a period of 10 seconds. ${ }^{6}$

The physical parameters were assessed using Student's ttest.

\section{Observation and Results}

The rats were divided into two groups, experimental and control. Each group was divided into 3 subgroups to assess 3 different parameters. The experimental group was exposed to prallethrin vapors for 6 months and physical activity parameters were assessed weekly.

\section{Physical Activity Parameters:}

a) Spontaneous Motor Activity:

No statistically significant changes were observed in the motor activity of the experimental subgroup as compared to control ones throughout the study (Figure1.1 and Table 1.4).

\section{b) Forced Locomotor Activity:}

This parameter also did not reveal any significant variation in the experimental group as compared to control group throughout the experiment (Figure 1.2 and Table 1.5 ).

\section{c) Swimming Endurance Test}

No statistically significant variation was observed between the experimental and control groups throughout the study (Figure 1.3 and Table 1.6).

\section{DISCUSSION}

\section{Physical activity and psychomotor parameter}

Neurotoxic effects of drugs are manifested as changes in behavioural and psychomotor functions as CNS controls number of functions like cognition, awareness, memory and motor functions. In our study, to evaluate the neurotoxic effects of inhaled pyrethroids rota rod test, swimming endurance test and spontaneous motor activity test was carried out. Significant changes in Spontaneous Motor Activity (Figure 1.1, Table1.4), Forced Locomotor Activity (Figure1.2, Table 1.5) and Swimming Endurance Test (Figure1.3, Table 1.6) were not recorded in prallethrin exposed rats as compared to control ones in the study. The body weight of experimental animals did not show any significant variation compared with control rats.

The studies by Ahlbom $^{7}$ using fat emulsion vehicle containing bioallethrin, which were administered orally as a single daily dose for 7 days to 10 day old mice offsprings. He observed a significantly reduced locomotion score which was different for each dosage group. Crofton and Reiter ${ }^{8}$ reported that decreased motor activity of rats is dosage dependent for type I and type II pyrethroids. Crofton ${ }^{9}$ reported exposure to deltamethrin produced dose dependent decrease in motor activity. They adopted two different routes of administration, intraperitoneal and per oral route. Motor activity being decreased more significantly in intraperitoneal as compared to per oral route. Abou donia ${ }^{10}$ reported decreased locomotor and sensorimotor performance in rats following exposure to pyridostigmine bromide, DEET, and permethrin using dermal or oral route. Manna ${ }^{11}$ found that after oral dosing of alfacypermethrin in rats, there was significant motor incoordination.

Talts $^{12}$ reported that neonatal exposure increases the susceptibility of adult mice to toxic effects of bioallethrin, if reexposed. Ahlbom ${ }^{7}$ also reported that exposure to an organophosphate (DFP) during a defined period in neonatal life induces permanent changes in brain muscarinic receptors and behaviour in adult mice. Wolansky ${ }^{13}$ studied the relative potencies for acute effects of pyrethroids on motor function in rats and found that all pyrethroids, regardless of structural class, produced dose dependent decreases in motor activity. The dosage and route of administration was acute and oral.

Sinha $^{2}$ reported that body weight of rat pups exposed to pyrethroid containing mosquito repellent decreased significantly but no gross abnormality in behaviour was observed. Tsuji ${ }^{14}$ also reported lack of changes in brain muscarinic receptor and motor activity of mice after neonatal inhalation exposure to d-Allethrin.

In view of these studies, it can be deduced that the physical activity and psychomotor performances, in case of pyrethroid exposure were governed by dose, age of the animal, duration of exposure and route of administration. Most common route of exposure to pyrethroids is through the inhalational method, oral intake being either accidental or suicidal. Hence in our study the inhalation administration method was adopted. Since the masses are being exposed to pyrethroid on a continuous basis that may extend upto 30 to 40 years, our 180 days study may be a limiting factor.

The higher level of sensitivity of the neonatal rat to pyrethroid toxicity is due to the incomplete development of the enzymes which catalyze the metabolism of pyrethroids in the liver of young animal. ${ }^{15}$

\section{CONCLUSION}

Neurotoxic effects of drugs are manifested as changes in physical activity and psychomotor functions as CNS controls 
number of functions like cognition, awareness, memory and motor functions. In our study, to evaluate the neurotoxic effects of inhaled pyrethroids rota rod test, swimming endurance test and spontaneous motor activity test was carried out. Lack of changes in the physical activity and psychomotor parameters as seen in our study suggest the relative safety of the said mosquito repellent. Our findings deviate from many of earlier studies as it may be due to difference in the route adopted and perhaps due to limited duration of exposure and high degree of adaptability of the animal to adverse insults. Further, study on the histological parameters is required to see if there is any abnormality in different areas of brain at microscopic level.

It appears that for the manifestation of abnormality in physical activity and other psychomotor parameters a further study with prolonged period of duration is required as in today's scenario the exposure to pyrethroid containing mosquito repellent is continued and chronic.

Conflict of Interest: None declared

\section{REFERENCES}

[1] Krieger RI, T.M. Dinoff, X. Zhang (2003) : Octachlorodipropyl ether (S-2) mosquito coils are inadequately studied for residential use in Asia and Illegal in the United States, Environ. Health Perspect. 111 1439-1442.

[2] Sinha C, Agarwal AK, Islam F, Seth K, Chatuvedi RK, Shukla S, Seth PK (2004): Mosquito repellent (pyrethroid- based) induced dysfunction of bloodbrain barrier permeability in developing brain. Int. J. Dev. Neurosci. $22(1), 31-37$.

[3] Kumar P and Kumar A (2009). Progress in Neuro-Psychopharmacology and Biological Psychiatry Volume 33, Issue 1, Pages 100-108.

[4] Kihara T (1991): Effects of the prenatal ochratoxin a exposure on behaviour of rat off spring.Acta Med Kinki Univ.Vol 16,No.1,1-22,1991.

[5] Trudeau F And Murphy R(1993): Effects of potassium-aspartate salt administration on glycogen use in the rat during a swimming stress. Physiology \& Behavior. Vol. 54, pp. 7-12.

[6] Dawson CA, Roemer RB And Horvath SM (1970): Journal of applied physiology.vol 29, No $2,150-154$.

[7] Ahlbom J, Fredriksson A, Eriksson P (1994): Neonatal exposure to a type I pyrethroid (bioaltethrin) induces dose response changes in brain muscarinic receptors and behaviour in neonatal and adult mice. Brain Res. 645: $318-324$

[8] Crofton KM and Reiter LW (1988): The effects of type 1 and II pyrethroids on motor activity and the acoustic startle response in the rat. Fundamental and Applied Toxicology Volume 10, Issue 4, May 1988, Pages 624-634.

[9] Crofton KM, Kehn LS, Gilbert ME (1995): Vehicle and route dependent effects of a pyrethroid insecticide, deltamethrin, on motor function in the rat. Neurotoxicology and Teratology Volume 17, Issue 4, July-August 1995, Pages 489-495

[10] Abou-Donia MB,Goldstein LB, Jones KH, Abdel-Rahman AA et al., (2001): Locomotor and Sensorimotor Performance Deficit in Rats following Exposure to Pyridostigmine Bromide, DEET, and Permethrin, Alone and in Combination. Toxicological Sciences 60, 305-314.

[11] Manna S (2005): Neuropharmacological effects of alfa-cypermethrin in rats Indian J Pharmacol, February 2005 , Vol 37, Issue 1, 18-20.

[12] Talts U, Fredriksson A, And Eriksson P (1998): Changes in Behavior and Muscarinic Receptor Density after Neonatal and Adult Exposureto Bioallethrin Neurobiology of Aging, Vol. 19, No. 6, pp. 545-552, 1998.

[13] Wolansky M J, Gennings C, and Crofton K M(2006): Relative Potencies for Acute Effects of Pyrethroids on Motor Function in Rats. Toxicological Sciences 89(1), 271-277.

[14] Tsuji,R., Kobayashi,K., Ik-eda,M., Yoshioka,T., Yamada,T., Seki, T., Ok-uno, Y., Nakatsuka,I., Tsuruo, Y., Kishioka,S., (2002): Lack of changes in brain muscarinic receptorand motor activity of mice after neonatal inhalation exposure to d-allethrin.J. Appl. Toxicol. 22, 423-429.

[15] Cantalamessa F(1993): Acute toxicity of two pyrethroids, permethrin, and cypermethrin in neonatal and adult rats Archives of Toxicology, Volume 67, Number 7, 510-513.

\section{AUTHORS}

First Author - Saim Hasan, Assistant professor, Department of Anatomy, SHKM GMC, Nalhar, Mewat, Haryana.

Second Author - Maheshwari T P, Senior resident, Department of Anatomy, SHKM GMC, Nalhar, Mewat, Haryana.

Correspondence Author - Saim Hasan, Assistant professor, Department of Anatomy, SHKM Govt. Medical College, Nalhar, Mewat, Haryana. 


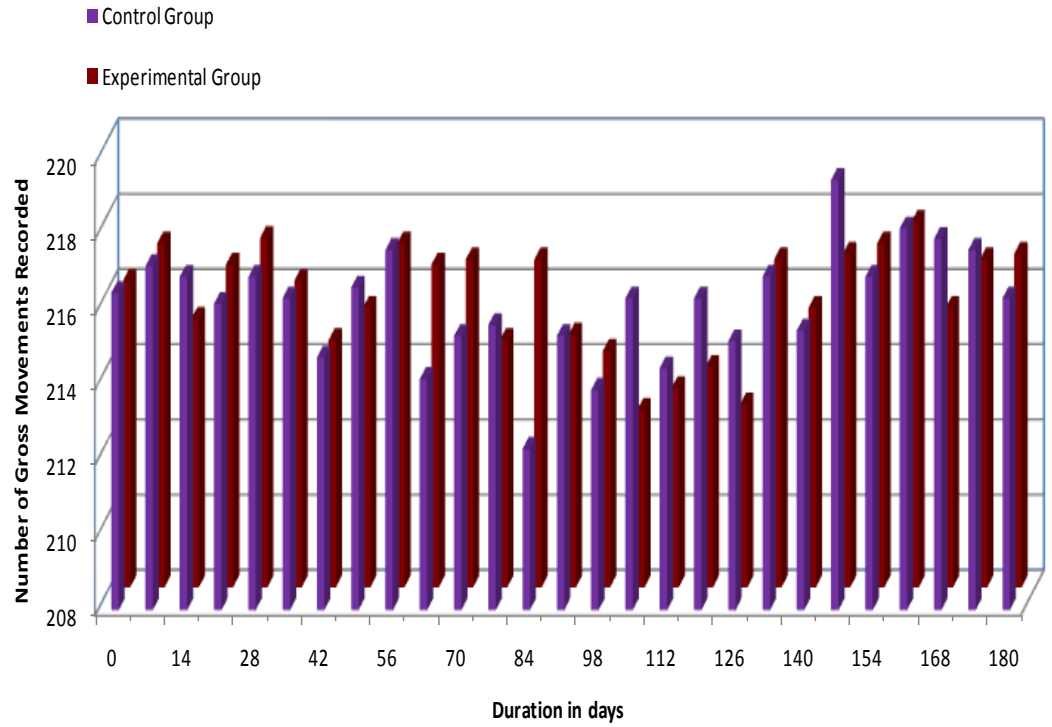

Figure 1.1. : Effect of Prallethrin vapours on spontaneous motor activity.

E control group

- experimental group

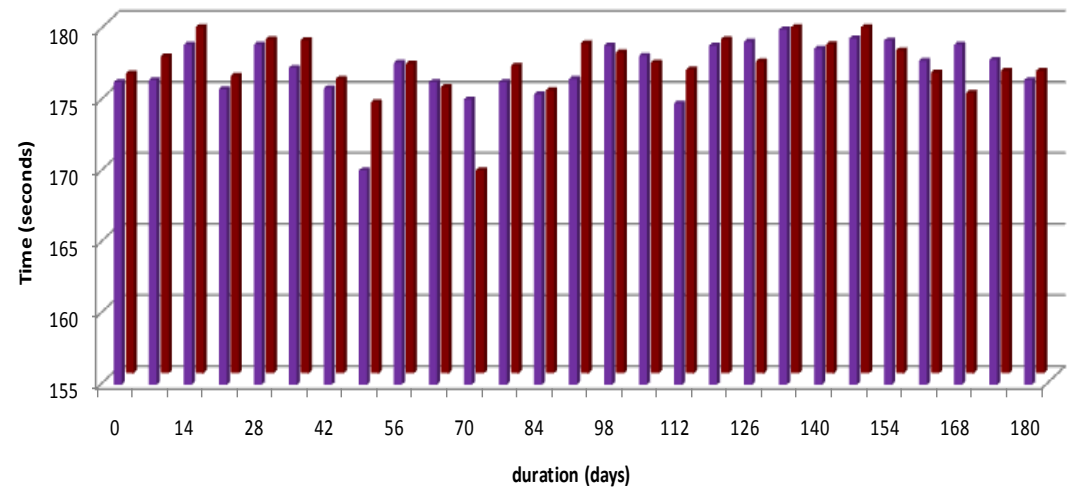

Figure 1.2 : Effect of prallethrin vapours on forced locomotor activity

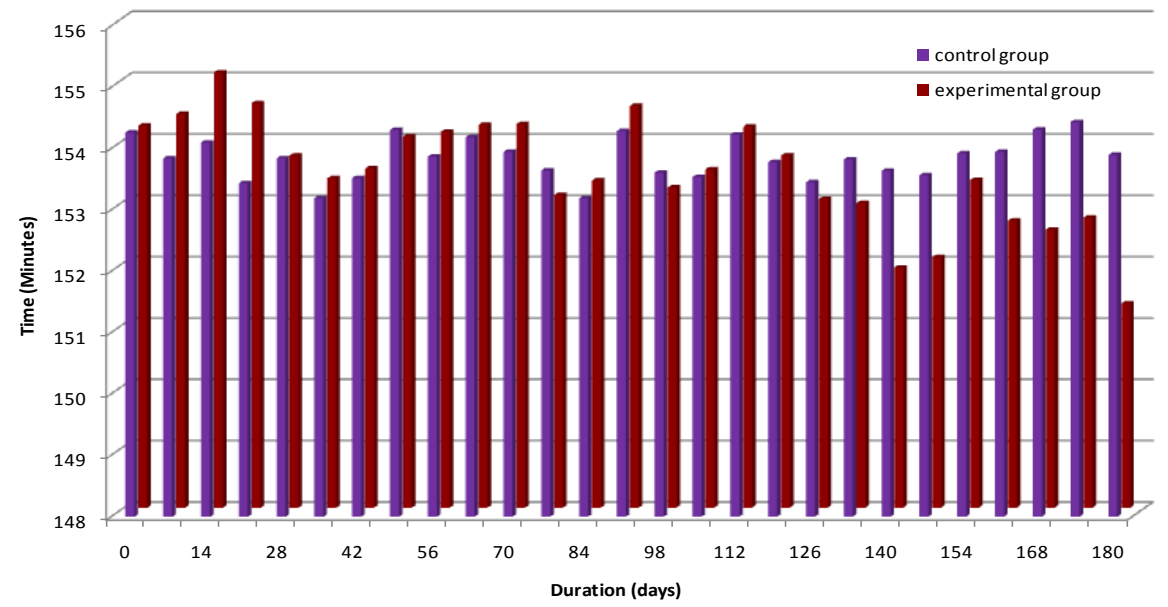

Figure 1.3 :Effect of prallethrin vapours on swimming endurance 


\begin{tabular}{|c|c|c|c|}
\hline \multirow{2}{*}{ Days } & \multicolumn{2}{|c|}{ Spontaneous Motor activity } & \multirow{2}{*}{ Significance } \\
\hline & Control & $\operatorname{Exp}$ & \\
\hline 0 & $216.42 \pm 4.61$ & $216.14 \pm 4.25$ & \multirow{27}{*}{ Not Significant } \\
\hline 7 & $217.14 \pm 7.68$ & $217.14 \pm 4.89$ & \\
\hline 14 & $216.85 \pm 6.08$ & $215.14 \pm 7.35$ & \\
\hline 21 & $216.14 \pm 8.31$ & $216.57 \pm 6.37$ & \\
\hline 28 & $216.85 \pm 4.90$ & $217.28 \pm 6.67$ & \\
\hline 35 & $216.28 \pm 5.31$ & $216.14 \pm 6.07$ & \\
\hline 42 & $214.71 \pm 5.41$ & $214.57 \pm 8.93$ & \\
\hline 49 & $216.57 \pm 5.00$ & $215.42 \pm 10.37$ & \\
\hline 56 & $217.57 \pm 3.35$ & $217.14 \pm 3.16$ & \\
\hline 63 & $214.14 \pm 4.67$ & $216.57 \pm 9.36$ & \\
\hline 70 & $215.28 \pm 6.28$ & $216.71 \pm 6.86$ & \\
\hline 77 & $215.57 \pm 5.75$ & $214.57 \pm 6.58$ & \\
\hline 84 & $212.28 \pm 8.05$ & $216.71 \pm 9.91$ & \\
\hline 91 & $215.28 \pm 4.90$ & $214.71 \pm 5.85$ & \\
\hline 98 & $213.85 \pm 3.23$ & $214.28 \pm 7.51$ & \\
\hline 105 & $216.28 \pm 4.60$ & $212.71 \pm 8.77$ & \\
\hline 112 & $214.42 \pm 5.24$ & $213.28 \pm 7.17$ & \\
\hline 119 & $216.28 \pm 4.10$ & $213.85 \pm 8.65$ & \\
\hline 126 & $215.14 \pm 4.33$ & $212.85 \pm 5.18$ & \\
\hline 133 & $216.85 \pm 3.39$ & $216.71 \pm 5.73$ & \\
\hline 140 & $215.42 \pm 4.29$ & $215.42 \pm 3.29$ & \\
\hline 147 & $219.42 \pm 3.16$ & $216.85 \pm 3.79$ & \\
\hline 154 & $216.85 \pm 4.90$ & $217.14 \pm 0.73$ & \\
\hline 161 & $218.14 \pm 3.77$ & $217.71 \pm 0.86$ & \\
\hline 168 & $217.85 \pm 3.98$ & $215.42 \pm 1.06$ & \\
\hline 175 & $217.57 \pm 3.31$ & $216.71 \pm 0.56$ & \\
\hline 180 & $216.28 \pm 2.16$ & $216.85 \pm 0.70$ & \\
\hline
\end{tabular}

(p 0.5 to 1.0)

Table 1.4: Effect of prallethrin vapours on spontaneous motor activity (Mean \pm S.E) 


\begin{tabular}{|c|c|c|c|}
\hline \multirow{2}{*}{ Days } & \multicolumn{2}{|c|}{ Forced Locomotor activity } & \multirow{2}{*}{ Significance } \\
\hline & Control & $\operatorname{Exp}$ & \\
\hline 0 & $176.28 \pm 2.01$ & $176.07 \pm 2.44$ & \multirow{27}{*}{ Not significant } \\
\hline 7 & $176.42 \pm 2.35$ & $177.28 \pm 1.39$ & \\
\hline 14 & $178.92 \pm 1.07$ & $179.35 \pm 0.64$ & \\
\hline 21 & $175.78 \pm 3.21$ & $175.92 \pm 1.57$ & \\
\hline 28 & $178.92 \pm 1.07$ & $178.50 \pm 1.20$ & \\
\hline 35 & $177.28 \pm 1.80$ & $178.42 \pm 0.92$ & \\
\hline 42 & $175.85 \pm 2.75$ & $175.71 \pm 2.54$ & \\
\hline 49 & $170.07 \pm 4.13$ & $174.07 \pm 3.15$ & \\
\hline 56 & $177.64 \pm 2.19$ & $176.78 \pm 1.80$ & \\
\hline 63 & $176.28 \pm 3.72$ & $175.14 \pm 2.37$ & \\
\hline 70 & $175.07 \pm 4.93$ & $169.28 \pm 10.24$ & \\
\hline 77 & $176.28 \pm 2.63$ & $176.64 \pm 2.75$ & \\
\hline 84 & $175.42 \pm 3.33$ & $174.92 \pm 2.07$ & \\
\hline 91 & $176.50 \pm 2.40$ & $178.21 \pm 1.48$ & \\
\hline 98 & $178.85 \pm 0.85$ & $177.57 \pm 1.60$ & \\
\hline 105 & $178.14 \pm 1.31$ & $176.85 \pm 1.16$ & \\
\hline 112 & $174.78 \pm 4.89$ & $176.35 \pm 1.12$ & \\
\hline 119 & $178.85 \pm 0.85$ & $178.50 \pm 1.50$ & \\
\hline 126 & $179.14 \pm 0.85$ & $176.92 \pm 2.00$ & \\
\hline 133 & $180.00 \pm 0.00$ & $179.35 \pm 0.64$ & \\
\hline 140 & $178.64 \pm 1.06$ & $178.14 \pm 0.91$ & \\
\hline 147 & $179.35 \pm 0.41$ & $179.35 \pm 0.64$ & \\
\hline 154 & $179.21 \pm 0.78$ & $177.71 \pm 0.71$ & \\
\hline 161 & $177.78 \pm 1.44$ & $176.14 \pm 1.05$ & \\
\hline 168 & $178.92 \pm 0.85$ & $174.71 \pm 2.15$ & \\
\hline 175 & $177.85 \pm 1.06$ & $176.28 \pm 1.26$ & \\
\hline 180 & $176.42 \pm 1.90$ & $176.28 \pm 1.25$ & \\
\hline
\end{tabular}

Table 1.5 :Effect of prallethrin vapours on forced locomotor activity (Mean \pm S.E) 


\begin{tabular}{|c|c|c|c|}
\hline \multirow{2}{*}{ Days } & \multicolumn{2}{|c|}{ Swimming Endurance Test } & \multirow{2}{*}{ Significance } \\
\hline & Control & Exp & \\
\hline 0 & $154.26 \pm 0.46$ & $154.22 \pm 0.33$ & \multirow{27}{*}{ Not significant } \\
\hline 7 & $153.84 \pm 0.66$ & $154.42 \pm 0.52$ & \\
\hline 14 & $154.10 \pm 0.41$ & $155.09 \pm 0.70$ & \\
\hline 21 & $153.43 \pm 0.43$ & $154.59 \pm 0.53$ & \\
\hline 28 & $153.84 \pm 0.76$ & $153.73 \pm 0.22$ & \\
\hline 35 & $153.19 \pm 0.61$ & $153.37 \pm 0.59$ & \\
\hline 42 & $153.52 \pm 0.43$ & $153.53 \pm 0.43$ & \\
\hline 49 & $154.30 \pm 0.55$ & $154.05 \pm 0.55$ & \\
\hline 56 & $153.87 \pm 0.43$ & $154.13 \pm 0.37$ & \\
\hline 63 & $154.18 \pm 0.53$ & $154.24 \pm 0.56$ & \\
\hline 70 & $153.94 \pm 0.74$ & $154.25 \pm 0.78$ & \\
\hline 77 & $153.64 \pm 0.63$ & $153.09 \pm 0.68$ & \\
\hline 84 & $153.19 \pm 0.61$ & $153.33 \pm 0.59$ & \\
\hline 91 & $154.28 \pm 0.41$ & $154.55 \pm 0.30$ & \\
\hline 98 & $153.60 \pm 0.61$ & $153.22 \pm 0.71$ & \\
\hline 105 & $153.53 \pm 0.43$ & $153.51 \pm 0.44$ & \\
\hline 112 & $154.23 \pm 0.55$ & $154.21 \pm 0.56$ & \\
\hline 119 & $153.78 \pm 0.48$ & $153.74 \pm 0.50$ & \\
\hline 126 & $153.45 \pm 0.51$ & $153.03 \pm 0.62$ & \\
\hline 133 & $153.82 \pm 0.65$ & $152.96 \pm 0.66$ & \\
\hline 140 & $153.64 \pm 0.51$ & $151.91 \pm 1.19$ & \\
\hline 147 & $153.56 \pm 0.69$ & $152.08 \pm 1.11$ & \\
\hline 154 & $153.92 \pm 0.47$ & $153.34 \pm 1.38$ & \\
\hline 161 & $153.95 \pm 0.65$ & $152.68 \pm 1.13$ & \\
\hline 168 & $154.31 \pm 0.45$ & $152.53 \pm 1.18$ & \\
\hline 175 & $154.43 \pm 0.49$ & $152.73 \pm 1.49$ & \\
\hline 180 & $153.90 \pm 0.50$ & $151.33 \pm 1.38$ & \\
\hline
\end{tabular}

(p 0.1 to 1.0)

Table 1.6: Effect of prallethrin vapours on swimming endurance (Mean \pm S.E) 